\title{
Influência de pontas de pulverização e adjuvantes no potencial de redução de deriva em túnel de vento
}

\section{Influence of spray nozzles and adjuvants in drift reduction potential in wind tunnel}

\author{
Rodolfo Glauber Chechetto ${ }^{1 *}$, Ulisses Rocha Antuniassi; \\ Alisson Augusto Barbieri Mota ${ }^{3}$; Fernando Kassis Carvalho \\ Anne Caroline Arruda e Silva ${ }^{3}$; Caroline Michels Vilela ${ }^{4}$
}

\begin{abstract}
Resumo
A deriva está diretamente ligada ao uso inadequado da tecnologia de aplicação de agrotóxicos, sendo a correta seleção das pontas de pulverização e adjuvantes importantes variáveis para auxiliar em sua redução. O objetivo deste trabalho foi estimar o potencial de deriva em túnel de vento com diferentes pontas de pulverização e diferentes concentrações de adjuvantes. O ensaio foi composto por seis caldas (óleo vegetal (em três concentrações), óleo mineral, surfatante e redutor de deriva), aplicadas com pontas de pulverização anti-deriva, jato plano com pré-orifício (DG 8003 VS) e indução de ar (AI $8003 \mathrm{VS}$ ). O equipamento utilizado foi um túnel de vento, onde as coletas de deriva foram realizadas em diferentes pontos. As médias dos tratamentos foram comparadas pelo Intervalo de Confiança, a $95 \%$ de probabilidade. A análise da porcentagem de deriva demonstrou que os tratamentos tiveram comportamentos distintos. O adjuvante nonil fenol etoxilado apresentou a maior deriva quando aplicado com a ponta de pré-orifício e a menor deriva quando aplicado com a indução de ar. Porém, comportamento contrário foi observado quando o adjuvante a base de óleo foi utilizado para as mesmas pontas. Para a ponta DG o menor percentual de deriva em todas as distâncias analisadas foi para o tratamento óleo vegetal $(1,0 \%)$ e para a ponta $\mathrm{AI}$ a menor deriva foi encontrada no tratamento com o adjuvante nonil fenol etoxilado $(0,0625 \%)$ nas quatro distâncias de coleta. Pode-se concluir que as pontas de pulverização e os adjuvantes testados alteram diretamente o potencial de deriva. Não houve proporcionalidade entre as concentrações do adjuvante a base de óleo vegetal testadas com a porcentagem de deriva.
\end{abstract}

Palavras-chave: Tecnologia de aplicação, surfatante, óleo vegetal, óleo mineral

\begin{abstract}
The drift is intimately linked to inappropriate use of pesticides and an important factor for reducing it, is the correct selection of spray nozzles and adjuvants. The objective of this work was to evaluate the drift potential in wind tunnel with different spray nozzles and different concentrations of adjuvants. The experiment was composed by six spray solutions (vegetable oil (in three concentrations), mineral
\end{abstract}

\footnotetext{
${ }^{1}$ Mestre em Agronomia-Energia na Agricultura, Universidade Estadual Paulista, UNESP, Campus de Botucatu, Botucatu, SP. E-mail: rgchechetto@hotmail.com

${ }^{2}$ Prof. Titular Dr. do Dept ${ }^{\circ}$ de Engenharia Rural, Faculdade de Ciências Agronômicas, UNESP, Botucatu, SP. E-mail: ulisses@fca. unesp.br

${ }^{3}$ Doutorando (s) em Agronomia-Energia na Agricultura, UNESP, Botucatu, SP. E-mail: alisson_abm@hotmail.com; anne_ arruda845@hotmail.com

${ }^{4}$ Discente(s) de Mestrado em Agronomia-Energia na Agricultura, UNESP, Botucatu, SP. E-mail: fer.kassis@hotmail.com; carolvilela@hotmail.com

* Autor para correspondência
} 
oil, surfactant and reducing drift), which were applied with two nozzles, one pre-orifice flat fan (DG $8003 \mathrm{VS}$ ) and other with air induction (AI $8003 \mathrm{VS}$ ), totaling 12 treatments, with three repetitions. The equipment used was a wind tunnel, where the drift collections were made at different points. The treatments averages were compared using Confidence Interval at 5\% probability. The analysis of the percentage of drift showed that the treatments had different behaviors. The nonylphenol ethoxylate adjuvant presented the highest drift when applied with the nozzle of pre-orifice and the lowest drift when applied with the air induction. The behavior of these nozzles when the oil-based adjuvant was used showed apposite results to those obtained for the surfactant. For the DG nozzles the lowest percentage of drift, at all analyzed distances, was observed to the treatment with vegetable oil $(1.0 \%)$ and with the AI nozzles the lower drift was found for the treatment with nonylphenol ethoxylate $(0.0625 \%)$, for the four distances in the collection. The result showed that both the spray nozzles and adjuvants alter directly the drift potential. There was no proportionately between the concentration of the oil-based adjuvant and the drift percentage.

Key words: Application technology, surfactant, vegetal oil, mineral oil

\section{Introdução}

O uso inadequado dos agrotóxicos tem causado preocupação devido à contaminação ambiental, sendo a deriva a principal perda que acarreta esta contaminação (COSTA et al., 2007). A deriva é conceituada por vários autores de forma similar, Christofoletti (1999) define deriva como tudo àquilo que não atinge o alvo. Já Miller (1993) define deriva como a parte de uma aplicação agrícola que é carregada para fora da área alvo, pela ação do vento. Completando, Miller (2004) afirma que o agrotóxico também pode ser transportado, na forma de deriva, em gotas ou na forma de vapor.

Alguns fatores indesejáveis causados pela deriva foram descritos por Ozkan (2001), como o uso ineficiente do equipamento e do tempo de trabalho do operador; o aumento da dose para suprir a perda por deriva; as aplicações com subdose do agrotóxico e controle ineficaz de pragas, doenças e plantas daninhas, necessitando aplicações adicionais, diminuindo o rendimento e aumentando os custos; a destruição obrigatória da cultura impedindo a colheita devido à contaminação não intencional de comestíveis "in natura"; os problemas e perdas jurídicas devido a danos causados a culturas sensíveis pertencentes a outros agricultores; a contaminação da água e do ar; e os riscos de afetar a saúde dos seres vivos.

A tecnologia de aplicação é um importante meio na redução da deriva, como a seleção correta de pontas de pulverização, por exemplo, as de baixa deriva (OZKAN, 2001; NUYTTENS et al., 2006), como as pontas com pré-orifício, que apresentam um perfil de gotas finas a grossas, e as com indução de ar, por produzirem um perfil de gotas grossas e/ ou muito grossas, com a presença de bolhas de ar em seu interior.

Quando se seleciona pontas de pulverização para uma determinada aplicação, o tamanho de gotas é muito importante, haja vista que existe uma variação do alvo e das condições climáticas. Porém, a maioria dos agricultores não se atenta para esse fator, realizando aplicações com baixa eficiência e com alto potencial de deriva.

Entre muitos fatores que afetam a deriva estão as propriedades físicas e químicas das caldas (BUTLER ELLIS; BRADLEY, 2002), e como um dos responsáveis por alterar estas características estão os adjuvantes, que modificam o espectro de gotas e resultam na variação do potencial risco de deriva (OLIVEIRA, 2011).

Dentre os adjuvantes, os surfatantes são amplamente utilizados, atuando no contato entre as gotas e a superfície, aumentando a taxa de absorção devido à redução da característica física da tensão superficial, exercendo um espalhamento mais uniforme, reduzindo a evaporação e aumentando o tempo de retenção da pulverização no alvo (TU; RANDALL, 2003). Já os óleos adjuvantes, mineral e vegetal, podem aumentar a penetração dos 
herbicidas em contato com a superfície foliar e são comumente usados quando as condições climáticas são quentes e secas e/ou quando as cutículas foliares são espessas (TU; RANDALL, 2003).

Uma importante ferramenta para o estudo da quantificação de deriva ou do potencial risco de deriva é o túnel de vento, que simula as condições de vento observadas em campo, permitindo selecionar e desenvolver técnicas de aplicação, como pontas de pulverização e adjuvantes, que reduzem o impacto ambiental e econômico causado pela perda de agrotóxicos (PHILLIPS; MILLER, 1999; DERKSEN et al., 1999; HERBST, 2001; FIETSAM; YOUNG; STEFFEN, 2004; COSTA, 2006).

Sabendo da importância das pontas de pulverização e dos adjuvantes nas aplicações de agrotóxicos, o objetivo deste trabalho foi estimar o potencial de deriva em túnel de vento com diferentes pontas de pulverização e diferentes concentrações de adjuvantes.

\section{Material e Métodos}

O presente trabalho foi realizado na Fazenda Experimental Lageado, da Faculdade de Ciências Agronômicas - UNESP, em Botucatu - SP, no Laboratório de Máquinas para Pulverização do Núcleo de Ensaio de Máquinas e Pneus Agrícolas (NEMPA).

A Tabela 1 traz as descrições dos adjuvantes utilizados no ensaio e as respectivas abreviaturas utilizadas para identificar os tratamentos. As pontas utilizadas foram a jato plano com pré-orifício DG 8003 VS e a jato plano com indução de ar AI 8003 VS, ambas a pressão constante de 4 bar, com gotas médias e muito grossas, respectivamente, segundo norma ASAE S572 (informação do fabricante). O experimento foi conduzido com 12 tratamentos (combinação de fatores), 2 pontas e 6 caldas com 3 repetições.

Tabela 1. Descrição e abreviaturas dos adjuvantes utilizados para quantificação de deriva em túnel de vento.

\begin{tabular}{|c|c|c|c|c|}
\hline Nome comercial & Composições & Fabricante & $\mathrm{g} \mathrm{L}^{-1}$ & Abreviações \\
\hline $\begin{array}{l}\text { Óleo Vegetal } \\
\text { emulsionável* }\end{array}$ & Óleo Vegetal & - & - & $\mathrm{OV}$ \\
\hline Nimbus & $\begin{array}{c}\text { Hidrocarbonetos alifáticos (Óleo } \\
\text { Mineral) }\end{array}$ & Syngenta & 428 & NB \\
\hline Li 700 & $\begin{array}{l}\text { Mistura de fosfatidicolina (Lecitina) e } \\
\text { Ácido propiônico }\end{array}$ & $\begin{array}{l}\text { De Sangosse } \\
\text { Agroquímica }\end{array}$ & 712,88 & LI \\
\hline In-Tec & Nonil fenol etoxilado & Inquima & 124,4 & IT \\
\hline
\end{tabular}

* Produto codificado fornecido pela Stoller do Brasil, cujas concentrações de óleo e emulsificantes não foram informadas.

Fonte: Elaboração dos autores.

O experimento foi realizado em laboratório com as condições climáticas monitoradas durante a execução de cada tratamento, respeitando as condições ideais limites de umidade relativa do ar acima de $55 \%$ e temperatura ambiente abaixo de $30^{\circ} \mathrm{C}$.

O percentual de deriva foi analisado em condições controladas em um túnel de vento de 4,8 $\mathrm{m}$ de comprimento e secção transversal de $0,56 \mathrm{~m}$ x 0,56 m, com área útil de aproximadamente 0,31 $\mathrm{m}^{2}$ e o comprimento da secção de testes de $2,5 \mathrm{~m}$ (MOREIRA JÚNIOR, 2009).

O sistema de pulverização foi composto por um reservatório de aço inox com capacidade de 15 litros, onde as caldas testadas foram armazenadas e pressurizadas por um cilindro de gás comprimido 
$\left(\mathrm{CO}_{2}\right)$. O sistema ainda dispunha de uma válvula anti-gotejo e um bico, composto de capa, anel de vedação, filtro (malha 50) e a ponta de pulverização a ser avaliada. O sistema ainda era composto por três manômetros, dois monitoravam a pressão de trabalho e um a pressão interna do gás no cilindro: na saída do cilindro de ar comprimido ficavam localizados dois deles e outro antes do conjunto do bico pulverizador. O controle do fluxo de calda era realizado manualmente através de uma válvula de abertura e fechamento tipo esfera. A ponta de pulverização era posicionada dentro do túnel de vento através de um orifício na parte superior, a altura de $0,44 \mathrm{~m}$ em relação ao piso do túnel, e foi anexada a um suporte tipo tripé com graduação, onde era possível posicioná-lo durante os testes de maneira desejada, para que o jato da pulverização chegasse ao piso do túnel de vento aberto.

Para a formulação das caldas de pulverização, foi utilizada água destilada à temperatura ambiente, e para todos os tratamentos foi utilizado o corante (traçador) artificial para fins alimentício Azul Brilhante FCF do fabricante Sensient Colors/ USA na concentração de $0,6 \% \mathrm{v} \mathrm{v}^{-1}$. A pesagem do corante foi realizada em balança de precisão de 0,0001 gramas da marca BEL, modelo 210A. A balança foi ligada e após 30 minutos as pesagens foram efetuadas. Este processo foi adotado para que os circuitos da balança entrassem em equilíbrio térmico, diminuindo assim possíveis erros de flutuações das medidas realizadas.

Esse corante apresenta baixa toxicidade e é um produto altamente solúvel em água. Trabalhos com esse corante foram realizados por Derksen et al. (1999); Paladini (2000); Moreira Júnior (2009) e Oliveira (2011), com bons resultados nos respectivos experimentos para medidas de deposição.

O fluxo de ar foi mantido na velocidade de 2 $\mathrm{m} \mathrm{s}^{-1}$, segundo metodologia descrita por Moreira Júnior (2009). Cada aplicação era efetuada durante 10 segundos, determinado por meio de um cronômetro digital e o fluxo da pulverização ocorreu pela abertura e fechamento da válvula tipo esfera de forma manual. Após o desligamento do ventilador foram aguardados 5 minutos, tempo estimado para total estabilização do ambiente dentro da seção de testes e fixação das gotas depositadas nos coletores.

Os coletores utilizados no ensaio foram fios de polietileno com diâmetro de $2 \mathrm{~mm}$ e dispostos no túnel de acordo com Oliveira (2011). Esses foram retirados do túnel de acordo com a distribuição na seção de testes com o auxílio de quatro pessoas, sendo uma para a retirada dos fios coletores do interior do túnel, com o auxílio de dois alicates, outras duas pessoas para efetuar os cortes nos fios do lado externo do túnel e uma para acondicionar os fios em sacos plásticos transparentes devidamente identificados. Posteriormente, esses sacos plásticos foram acondicionados no interior de outros sacos plásticos, de cor escura, para uma maior proteção das amostras contra umidade e luminosidade.

Para a etapa de lavagem dos fios coletados, foram adicionados $15 \mathrm{~mL}$ de água destilada dentro dos sacos plásticos transparentes, que acondicionavam os fios e estes foram agitados manualmente até total remoção do corante presente nas amostras. A medida de água adicionada para a lavagem das amostras foi realizada por meio de um dispensador com precisão de $0,01 \mathrm{~mL}$. Após essa etapa, o líquido foi colocado em recipientes de plástico de $100 \mathrm{~mL}$, também devidamente identificados e com tampas.

Os líquidos armazenados nos recipientes plásticos foram analisados em um espectrofotômetro modelo UV-1601PC, marca Shimadzu. Os resultados em absorbância para o corante Azul Brilhante foram analisados em $630 \mathrm{~nm}$ de comprimento de onda, que foram transformados em ppm por meio de confecção de curvas-padrão a partir de concentrações conhecidas, coletadas das caldas que compuseram os tratamentos. Os depósitos provenientes de cada posição de coleta no túnel de vento foram avaliados individualmente, possibilitando representar a distribuição dos tratamentos analisados em toda a seção de testes, conforme Moreira Júnior (2009) 
e Oliveira (2011). Os resultados dos tratamentos foram comparados pelo Intervalo de Confiança para Diferenças entre as Médias, a 5\% de probabilidade (IC95\%).

\section{Resultados e Discussão}

Os valores médios de deriva (\%) para os tratamentos aplicados com a ponta DG (Figura 1) variaram entre 0,046 a $0,17 \%$. Na comparação com o tratamento NB $(0,5 \%)$, todos os tratamentos ocasionaram aumento do valor médio de deriva, indicando potencial para aumento no risco de deriva da aplicação. A única exceção foi o tratamento OV $(1,0 \%)$ que proporcionou menor deriva na comparação com o NB (0,5\%). Observa-se que a maior deriva foi encontrada para o tratamento com o surfatante a base de nonil fenol etoxilado (IT a $0,0625 \%$ ), apresentando diferença significativa para todos os demais tratamentos, seguido do tratamento OV $(0,6 \%)$ que não apresentou diferença somente para o tratamento LI $(0,15 \%)$.

Figura 1. Porcentagem de Deriva (médias $\pm \mathrm{IC}_{5 \%}$ ) analisada para os adjuvantes com a ponta de jato plano com préorifício (DG).

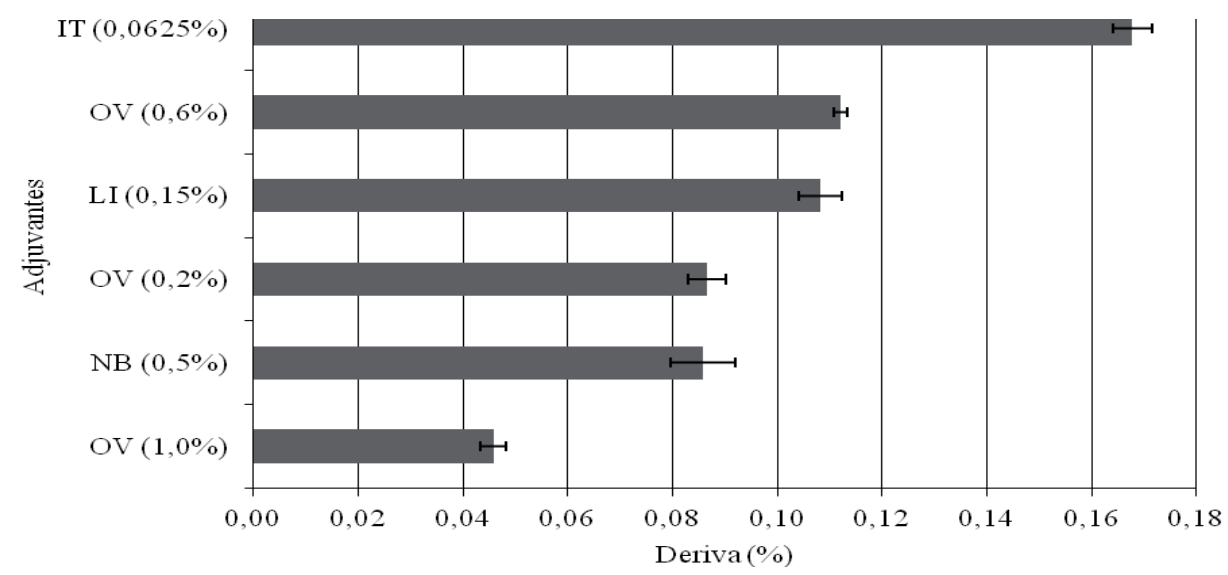

Fonte: Elaboração dos autores.

O menor valor de deriva foi observado para o tratamento OV $(1,0 \%)$ diferindo dos demais tratamentos. Constata-se também que o tratamento LI $(0,15 \%)$, produto classificado como redutor de deriva, reduziu esse fator somente em relação ao tratamento IT $(0,0625 \%)$, sendo importante um maior conhecimento desse produto para uma correta utilização com a ponta DG. Segundo Antuniassi (2006), as características de uma pulverização podem ser alteradas de forma significativa pelo uso de variadas formulações e pela adição de adjuvantes, como a observada neste trabalho, o que muitas vezes passa despercebido.

Os valores médios de deriva (\%) para os tratamentos aplicados com a ponta AI (Figura 2) variaram entre 0,026 a $0,052 \%$, mostrando diferenças na comparação direta com o DG $(0,046$ a $0,17 \%)$. Entretanto, é preciso observar que para os tratamentos LI $(0,15 \%)$, NB $(0,5 \%)$ e OV $(1,0 \%)$, os valores de deriva se aproximaram dos valores mínimos encontrados para a ponta DG.

Ainda quanto a ponta AI, na comparação com o tratamento NB (0,5\%), todos os demais tratamentos ocasionaram redução do valor médio de deriva, indicando potencial para redução no risco de deriva da aplicação. A única exceção foi o tratamento LI $(0,15 \%)$ que proporcionou maior deriva na comparação com o NB (0,5\%). Neste sentido, 
o tratamento LI $(0,15 \%)$ apresentou diferença significativa somente para os tratamentos $\mathrm{OV}$ $(0,6 \%)$, OV $(0,2 \%)$ e IT $(0,0625 \%)$.

Costa (2006) avaliando deriva de uma ponta de pulverização com pré-orifício (DG) encontrou redução significativa na deriva gerada pelo tratamento com óleo vegetal $(1,0 \%)$ quando comparado com óleo mineral $(1,0 \%)$, na distância de 2 metros em relação à ponta de pulverização. No presente estudo também foi observado esta tendência, ou seja, o tratamento com óleo vegetal
$(1,0 \%)$ reduziu significativamente a deriva quando comparado com o tratamento a base de óleo mineral (NB 0,5\%). O mesmo autor, avaliando deriva para a ponta de jato plano com indução de ar (AI) não notou diferença para os tratamentos com óleo vegetal e óleo mineral nas distâncias de coleta avaliadas. O mesmo resultado foi encontrado no presente estudo, onde os tratamentos com óleo vegetal nas três concentrações avaliadas não apresentou diferença significativa para o tratamento com óleo mineral.

Figura 2. Porcentagem de Deriva (médias $\pm \mathrm{IC}_{5 \%}$ ) analisada para os adjuvantes com a ponta de jato plano com indução de $\operatorname{ar}(\mathrm{AI})$.

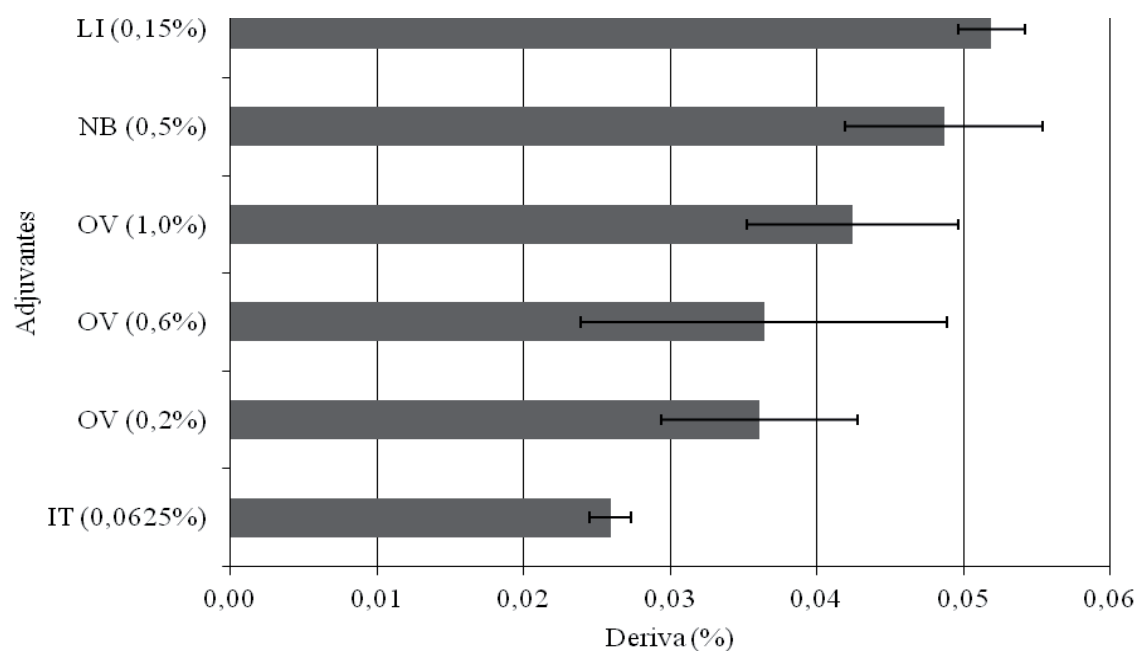

Fonte: Elaboração dos autores.

Para efeito de comparação entre as pontas de pulverização utilizadas no experimento, os adjuvantes foram separados em 4 classes (Figura 3), sendo eles, óleo vegetal (OV), onde os valores de deriva foram agrupados numa média para as três concentrações, óleo mineral (NB 0,5\%), surfatante (IT $0,0625 \%)$ e o redutor de deriva LI $(0,15 \%)$. Os valores estão apresentados como médias dos índices de deriva determinados no túnel de vento.

Analisando individualmente a ponta AI, nota-se que a classe surfatante apresentou o menor valor de deriva, com diferença significativa. Já as demais classes analisadas não apresentaram diferença significativa entre si. Para a ponta DG o menor valor total de deriva foi o encontrado na classe dos óleos vegetais, que não diferiu do óleo mineral. O maior valor total de deriva para a ponta com pré-orifício foi o encontrado para a classe surfatante, diferindo estatisticamente de todas as outras avaliadas. É importante ressaltar, como observado na Figura 3, o comportamento inverso do surfatante quando pulverizado com as pontas DG e AI. Comparandose com uma média dos demais tratamentos, o surfatante promoveu aumento na deriva para a 
ponta $\mathrm{DG}$ e redução para a ponta $\mathrm{AI}$, indicando uma inversão em sua característica funcional de acordo com o tipo de ponta utilizado.

O surfatante apresentou a maior redução da deriva quando houve a mudança da ponta com pré-orifício para a ponta com indução de ar. Os resultados deste trabalho corroboram com os apresentados por Derksen et al. (1999) e Lund (2000), onde os menores valores de deriva em túnel de vento foram encontrados para as pontas com indução de ar. Com a mesma linha de resultados, em estudo de campo, Nuyttens et al. (2006) encontraram valores reduzidos de deriva para as pontas com indução de ar.

Figura 3. Porcentagem de Deriva (médias $\pm \mathrm{IC}_{5 \%}$ ) analisada para os grupos de adjuvantes com as pontas de jato plano com pré-orifício (DG) e indução de ar (AI).

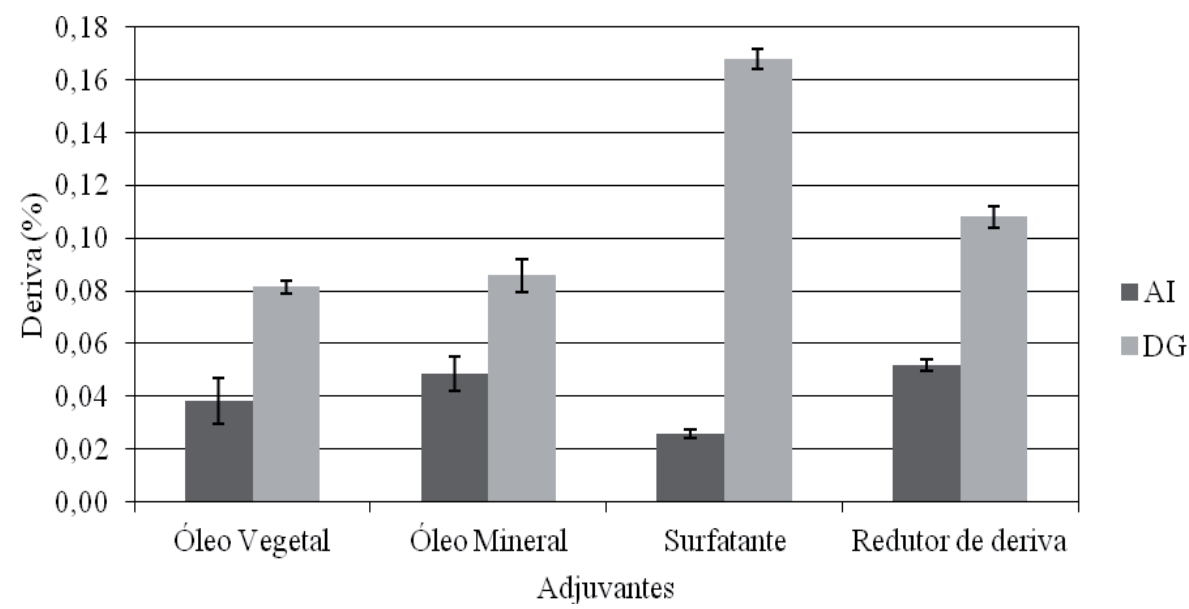

Fonte: Elaboração dos autores.

Esses resultados são explicados em trabalho de Miller e Butler Ellis (2000), em que a utilização de surfatantes com pontas de indução de ar promove um aumento do DMV das gotas, reduzindo assim o potencial risco de deriva, porém, efeito contrário é observado quando um surfatante é utilizado com outro tipo de ponta, onde o DMV é reduzido, aumentando o potencial risco de deriva. No mesmo sentido, em estudo de Moreira Júnior (2009) foram encontrados os maiores níveis de deriva para o tratamento com o surfatante, que foi aplicado com uma ponta de jato plano padrão (XR 8003).

Valores menores na redução da deriva, porém significativos, foram encontrados para as demais classes de adjuvantes, quando se alterou a ponta de jato plano com pré-orifício para a ponta de jato plano com indução de ar. Já na alteração dos adjuvantes em uma mesma ponta é possível analisar vários níveis de deriva, já que isto ocorre devido à alteração das propriedades físico-químicas das caldas promovidas pelos adjuvantes (SANDERSON et al., 1997; FIETSAM; YOUNG; STEFFEN, 2004).

O percentual de deriva avaliado conforme as distâncias dos coletores, para as diferentes caldas testadas, com a ponta de jato plano com pré-orifício estão apresentados na Figura 4. Para a ponta DG o menor percentual de deriva em todas as distâncias analisadas foi para o tratamento OV $(1,0 \%)$ e o maior valor do percentual de deriva foi para o tratamento IT $(0,0625 \%)$. Com a redução desse percentual quando se compara a menor distância de coleta $(1,0 \mathrm{~m})$ em relação à maior distância $(2,5$ 
m), observa-se a capacidade do óleo vegetal $(1,0 \%)$ na redução do percentual de deriva à medida que aumentamos a distância de coleta, notadamente na comparação com o surfatante à base de nonil fenol etoxilado.

Observa-se uma tendência semelhante em todos os tratamentos analisados para a ponta DG, sendo que, o aumento da distância de coleta em relação à ponta de pulverização proporciona uma diminuição da percentagem de deriva. Esse mesmo comportamento foi analisado em estudos de túnel de vento por Lund (2000), Costa (2006), Moreira Júnior (2009) e Oliveira (2011).

Figura 4. Porcentagem de Deriva (médias $\pm \mathrm{IC}_{5 \%}$ ) analisada para os adjuvantes com a ponta de jato plano com préorifício (DG).

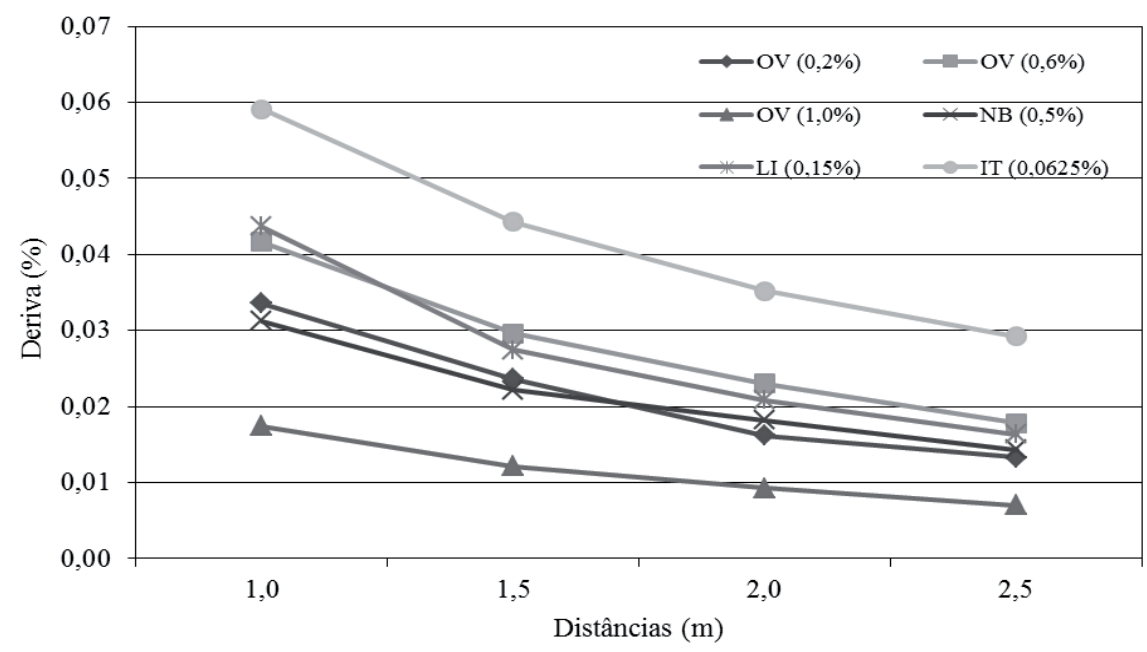

Fonte: Elaboração dos autores.

Na Figura 5 estão apresentados os percentuais de deriva avaliados conforme as distâncias dos coletores, para as diferentes caldas testadas, com a ponta de jato plano com indução de ar. Nota-se que a maior deriva foi avaliada para o tratamento LI $(0,15 \%)$ em três das quatro distâncias, sendo superado somente na distância de 2,0 m em relação à ponta de pulverização pelo tratamento $\mathrm{NB}(0,5 \%)$. A menor deriva foi encontrada no tratamento com o adjuvante a base de nonil fenol etoxilado $(0,0625 \%)$ nas quatro distâncias de coleta. Nota-se que a ponta AI apresenta uma maior redução da deriva quando comparado à ponta de jato plano com pré-orifício (DG) em relação à menor e a maior distância da ponta de pulverização.
A mesma tendência encontrada para a ponta DG é mantida para a ponta $\mathrm{AI}$, em que, quanto maior a distância avaliada em relação à ponta de pulverização menor é a deriva. Em relação ao tratamento com o surfatante, o mesmo comportamento encontrado para a soma total de deriva é observado de forma coerente nas análises das distâncias, em que a ponta de jato plano com indução de ar apresenta o menor valor nesse parâmetro, já para a ponta de jato plano com pré-orifício o maior valor de deriva é relacionado a esse produto, confirmando, novamente, o estudo de Miller e Butler Ellis (2000). 
Figura 5. Porcentagem de Deriva para os tratamentos, na ponta de jato plano com indução de ar (AI), em função das distâncias de coleta dentro do túnel de vento.

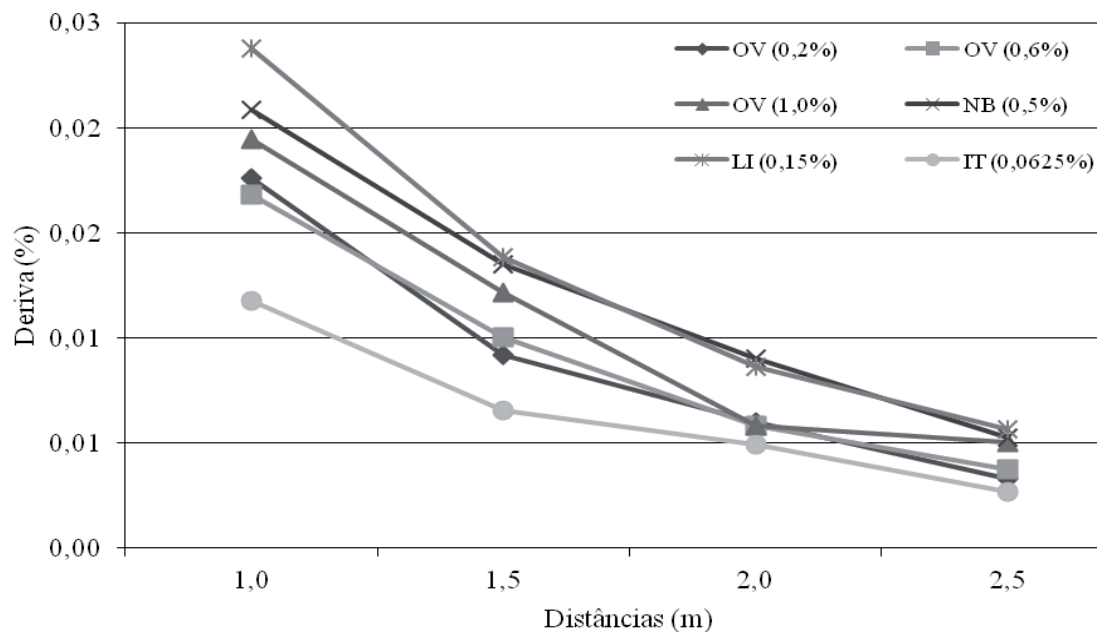

Fonte: Elaboração dos autores.

\section{Conclusões}

As pontas de pulverização e os adjuvantes testados alteram diretamente o potencial de deriva em túnel de vento para todos os tratamentos.

A associação da ponta com indução de ar mais o adjuvante a base de nonil fenol etoxilado apresenta o menor potencial de deriva.

Não houve proporcionalidade entre as concentrações do adjuvante a base de óleo vegetal com a porcentagem de deriva.

\section{Referências}

ANTUNIASSI, U. R. Tecnologia de aplicação de defensivos. Revista Plantio Direto, Passo Fundo, v. 15, n. 4, p. 17-22, 2006.

BUTLER ELLIS, M. C.; BRADLEY, A. The influence of formulation on spray drift. International Advances in Pesticide Application, Cambridge, v. 66, n. 4, p. 251-258. 2002.

CHRISTOFOLETTI, J. C. Considerações sobre a deriva nas pulverizações agrícolas e seu controle. São Paulo: Teejet South América, 1999. 15 p.
COSTA, A. G. F. Determinação da deriva da mistura 2,4$D$ e glyphosate com diferentes pontas de pulverização $e$ adjuvantes. 2006. Tese (Doutorado em Agronomia) - Faculdade de Ciências Agronômicas. Universidade Estadual Paulista, Botucatu.

COSTA, A. G. F.; VELINI, E.D.; NEGRISOLI, E.; CARBONARI, C. A.; ROSSI, C. V. S.; CORRÊA, M. R.; SILVA, F. M. L. Efeito da intensidade do vento, da pressão e de pontas de pulverização na deriva de aplicações de herbicidas em pré-emergência. Planta Daninha, Viçosa, v. 25, n. 1, p. 203-210, jan./mar. 2007.

DERKSEN, R. C. R. C.; OZKAN, H. E.; FOX, R. D.; BRAZEE, R. D. Droplet spectra and wind tunnel evaluation of venturi and pre-orifice nozzles. Transactions of the ASABE, Saint Joseph, v. 42, n. 6, p. 1573-1580, 1999.

FIETSAM, J. F. W.; YOUNG, B. G.; STEFFEN, R. W. Herbicide drift reduction to drift control agents with glyphosate. Transactions of the ASABE, Saint Joseph, v. 47, n. 5, p. 1405-1411, 2004.

HERBST, A. A method to determine spray drift potential from nozzles and its link to buffer zone restrictions. Saint Joseph: ASAE Meeting Presentation, 2001. 1047 p.

LUND, I. Nozzles for drift reduction. Aspects of Applied Biology, Wellesbourne, v. 57, n. 1, p. 97-102, 2000.

MILLER, P. C. H. Reducing the risk of drift from boom sprayers. In: RAETANO, C. G.; ANTUNIASSI, U. R. Qualidade em tecnologia de aplicação. Botucatu: FEPAF, 2004. p. 110-124. 
Spray drift and its measurement. In: MATTHEWS, G. A.; HISLOP, E. C. Application technology for crop protection. London: CAB International, 1993. p. 101-122.

MILLER, P. C. H.; BUTLER ELLIS, M. C. Effects of formulation on spray nozzle performance for applications from ground-based boom sprayers. Crop Protection, Guildford, v. 19, p. 609-615, 2000.

MOREIRA JÚNIOR, O. Construção e validação de um túnel de vento para ensaios de estimativa da deriva em pulverizações agrícolas. 2009. Tese (Doutorado em Agronomia/Energia na Agricultura) - Faculdade de Ciências Agronômicas. Universidade Estadual Paulista, Botucatu.

NUYTTENS, D.; SCHAMPHELEIRE, M. de; STEURBAUT, W.; BAETENS, K.; VERBOVEN, P.; NICOLAÏ, B.; RAMON, H.; SONCK, B. Experimental study of factors influencing the risk of drift from field sprayers, Part 1: Meteorological conditions. Aspects Applied Biology, Wellesbourne, v. 77, n. 2, p. 321-329, 2006.
OLIVEIRA, R. B. Caracterização funcional de adjuvantes em soluções aquosas. 2011. Tese (Doutorado em Agronomia/Energia na Agricultura) - Faculdade de Ciências Agronômicas. Universidade Estadual Paulista, Botucatu.

OZKAN, H. E. Reduzindo a deriva nas pulverizações. 2001. Disponível em: <http://www.comam.com.br>. Acesso em: 17 jul. 2001.

PALADINI, L. A. Metodologia para avaliação da deposição em pulverizações. 2000. Tese (Doutorado em Proteção de Plantas) - Faculdade de Ciências Agronômicas. Universidade Estadual Paulista, Botucatu.

PHILLIPS, J. C.; MILLER, P. C. H. Field and wind tunnel measurements of the airborne spray volume downwind of single flat-fan nozzles. Journal of Agricultural Engineering Research, London, v. 72, p. 161-170, 1999.

SANDERSON, R.; HEWITT, A. J.; HUDDLESTONT, E. W.; ROSS, J. B. Relative drift potential and droplet size spectra of aerially applied propanil formulations. Crop Protection, Guildford, v. 16, n. 8, p. 717-721, 1997.

TU, M.; RANDALL, J. M. Adjuvants. In: TU, M.; HURD, C.; RANDALL, J. M. Weed control methods handbook the nature conservancy. Davis: TNC, 2003. p. $1-24$. 